Journal of Economics and Behavioral Studies

Vol. 5, No. 9, pp. 580-587, Sep 2013 (ISSN: 2220-6140)

\title{
A Matter of Intercultural Communication: Perspectives of International Students at a University in South Africa
}

\author{
*V.P. Rawjee, K. Reddy, M. Maharaj \\ Durban University of Technology, South Africa \\ *rawjeeve@dut.ac.za
}

\begin{abstract}
The end of apartheid in South Africa in 1994 saw many higher education institutions identifying opportunities to increase their intake of international students by introducing student exchange programmes. Based on South Africa's ethnically diverse society, cultural differences pose various challenges for international students. This results in intercultural communication apprehension and therefore, a negative experience for international students. The aim of this research is to examine the cultural challenges faced by international exchange students studying at a university in South Africa. A quantitative descriptive methodology was employed for this study. Themes emanating from the literature review were used to develop a research questionnaire that consisted mostly of closed-ended questions followed by a few open-ended questions. The questionnaire was administered to ninety nine international students. The findings of the investigation indicate that the majority of international students experience culture as a challenge, which impacted on their ability to communicate and to be understood. To add credence to the international students' experiences and the exchange programme, this paper therefore, suggests that issues around culture and intercultural communication is introduced as a core study module for all first-time international students before they arrive in South Africa.
\end{abstract}

Keywords: Intercultural communication, international exchange students, culture, acculturate

\section{Introduction}

Altbach \& Teichler (2001) state that academic exchange programme shave historically been a largely elitist enterprise. In the past, the vast majority of student exchange programmes involved students from Western countries studying in other Western countries. However, student mobility has grown in popularity in recent years as developments in communication infrastructure have evolved. The internet is bridging the global divide between countries and information is made freely available. For students, this means that study opportunities in foreign countries are easily accessible. After the end of apartheid in 1994, a multitude of study opportunities to South Africans and the international community within the context of higher education became available. International study in South Africa has increased, as pointed out by Kishun (2007), who maintains that the number of international students has more than quadrupled in recent years. The desire of international students to study in South Africa has become popular. Within this context, many universities moved to develop institutional strategies for internationalization (Taylor, 2004). One such initiative was student exchange programmes. These were developed in line with government-driven initiatives, which steered the country towards the international arena and the need for international acceptance; the ability to compete on a global scale and an increase in the need to encourage relations with the international community.

In 1999, a university in KwaZulu-Natal, South Africa, drove this initiative, through policy, by increasing the access to education to international students. A student exchange programme was identified and an international office was established. The aim of the programme is to establish a platform for students to participate in a reciprocal exchange programme. Local South African students study abroad, whilst international students study at the South African university in question for one semester. The students are responsible for paying fees directly to their home institutions and, in return, receive a waiver of fees at the elected host institution. The choice of country/university is governed by the negotiated agreements that are established between the institutions. Courses completed at the host institution are credited at the home institution. Despite the positive opportunities that student exchanges have created, Brown (2008) found that international students studying in foreign countries are experiencing increased stress levels. In addition to other factors, Brown (2008) attributes these stress levels to the need for a high level of English competency and the vast cultural differences between the host country and the student country. Critical questions that therefore remain are what are the cultural challenges faced by 
international students and what is the role of communication in helping to curb these challenges? The purpose of this study is to therefore examine the intercultural communication challenges faced by international exchange students studying at a university in South Africa.

\section{Literature Review}

Cultural challenges experienced by international exchange students: Bond and Lemasson (1999) mention that ideally higher education must do better to prepare its beneficiaries to think in both a global and differentiated context, help them take a cosmopolitan view, be more aware of cultural differences and promote an open, understanding mind. In many instances, foreign exchange programmes, to an extent, serve as a platform for cultural experiences that broaden perspectives and provide knowledge of a foreign language and civilization. Van Hoof and Verbeeten's (2005) study shows that most exchange students saw the greatest benefits of studying abroad was that it brought about a greater understanding of other cultures; led to a greater appreciation of their own culture; enabled them to learn more about themselves, and it enriched them personally. With its multi-cultural and diverse society, South Africa serves as an ideal platform for this experience. However, despite the many benefits that student exchange and study abroad programmes bring, a period of adaptation and acclimatization is required for international students (Brown, 2008). Brown (2009) further found that, at the start of their stay, most sojourners (people who visit or temporarily reside in another country) will experience some degree of culture shock. Culture shock is anxiety that results from losing all one's familiar signs and symbols of social intercourse. Chaney and Martin's (2007) example of culture shock explains how US travelers, experienced the frustration with culture, which included challenges with language, food and local customs; the unwillingness to understand the rationale behind the local ways of doing things and the labeling of behaviour as backward and inefficient without trying to understand the basis for the behaviour.

Jack London, in his 1900 story, "In a Far Country", explains that a visitor to another culture should be prepared to acquire new customs and abandon old ideals. Many foreign students, however, do not experience acculturation. They are resistant to abandoning their past and refuse to accept new ideas into their existing culture. For example, Gundykunst (1998) specifically identifies racial discrimination, weather and food differences, language, accommodation, separation from home, dietary restrictions, money, diminished social interactions, role and status change and different educational systems as sources of strain for foreign students. In addition, Persaud (1993) states that all students are challenged by the demands of higher education, but many international students are particularly placed under pressure by the confrontation of an alien culture. Toyokawa and Toyokawa (2002) state that, in the case of international students, culture shock includes language difficulties, adjustment to customs and values, differences in educational systems, isolation and loneliness, homesickness and a loss of established social networks. Chaney and Martin (2007),therefore, suggests that sojourners should find pleasure in the unfamiliar environment because those who could not fit into the new culture would either return home or "die" of both psychological and physical ailments.

Samovar, Porter and Daniel (2011), however, maintain that culture shock, to an extent, can be seen as a communication problem that involves the frustrations of not understanding the verbal and non-verbal communication of the host culture, its customs and its value systems. Lin and Rancer (2003) confirm that intercultural apprehension can be inversely correlated with a measure of "intercultural willingness to communicate". It seems that individuals with a high level of cultural communication apprehension would be more likely to have negative expectations of international contact situations and thus a negative studyabroad experience. Ballard and Clanchy (1997) states that, in the first three months of the academic sojourn, the greatest pressure relates to the ability to understand and be understood. This fear, combined with already high levels of anxiety of having to adapt to a new environment, could mean that misunderstandings in communication and, therefore, the basis for a negative experience. Chaney and Martin (2007) purport that resistance in accepting a new culture stemming from inadequate communication results in enormous personal struggle for the visiting student. They further observe that every cultural pattern and every single act of social behaviour involve communication. In this instance, communication may be regarded as the central and binding element which may help to alleviate cultural apprehension.

The role of intercultural communication: Jandt (2000) states that culture cannot be known without the study of communication and communication can only be understood with an understanding of the 
culture it supports. To be understood, the two must be studied together as intercultural communication. According to Samovar, Porter \& McDaniel (1991), intercultural communication occurs whenever a message is produced by a member of one culture for consumption by a member of another culture. In other words, intercultural communication is communication between people from different cultures. For international students to function in South Africa's multicultural environment as effectively and meaningfully as possible, they must be study culture and intercultural communication simultaneously. The ability to make sense of cultural values will promote effective intercultural communication. This will, to an extent, will help with making sense of experiences. Intercultural communication can, therefore, be seen as one of the solutions to helping to make the international student's experience a more positive one. During intercultural communication, it is, however, important not only to understand surface cultural values, but to also understand cultural values that are less visible. These values are explained by Funakawa's (1997) according to the Cultural Iceberg Model as depicted in Figure 1.

Figure 1: Cultural Iceberg model (Funakawa, 1997)

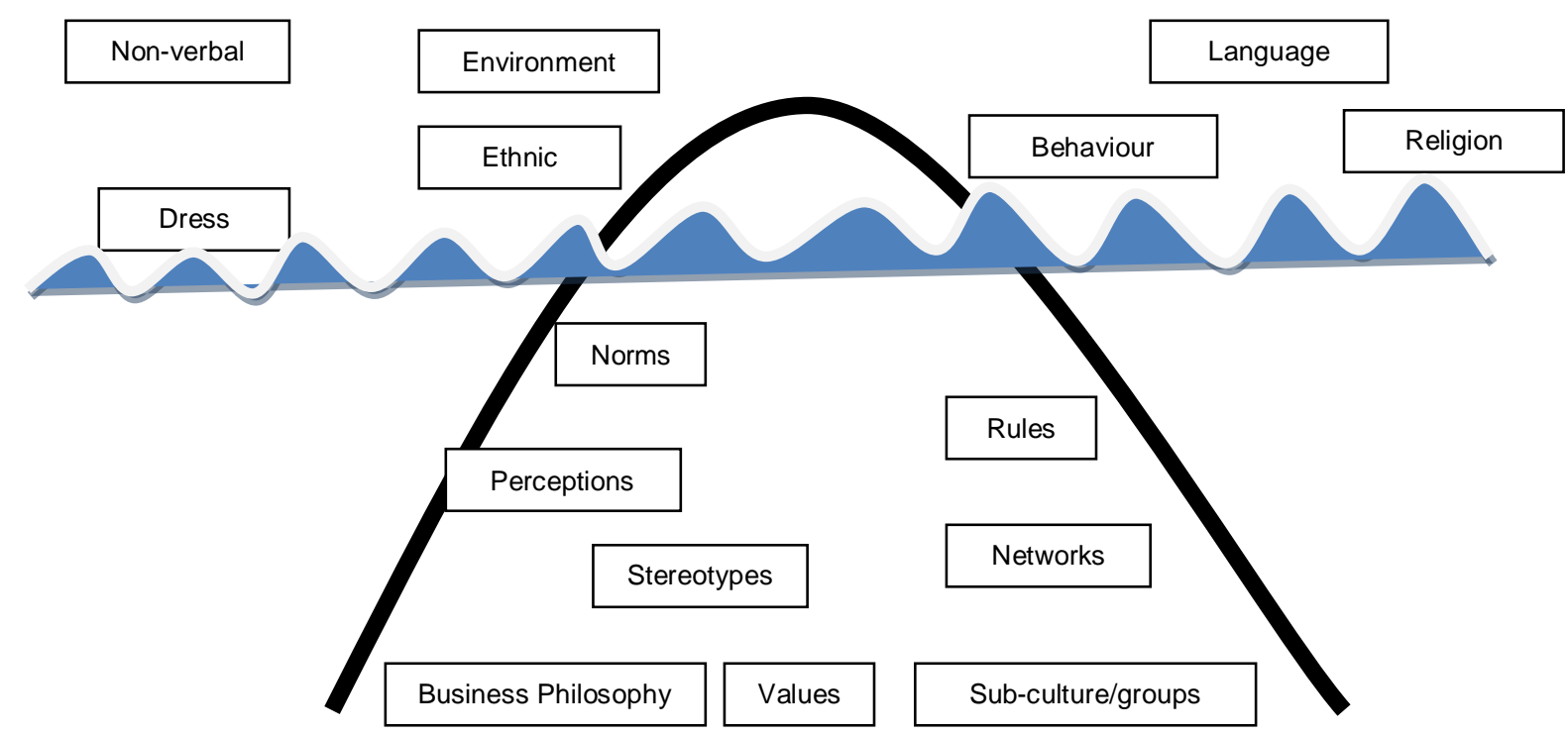

Funakawa (1997) explains, that an individual responds to surface values that he/she can sense which these includes one's environment; ethnic; dress; non-verbal; religion; language and behaviour. $\mathrm{He}$ further states that, to communicate effectively, one has to understand the cultural values below the 'waterline', which include norms; rules; networks; sub-culture groups; values; business philosophy; stereotypes and perceptions. The understanding of these values is necessary to build successful business relationships and to bring about cultural synergy. Therefore, when different cultures interact by considering cultural values below the 'waterline', diffusion of innovations takes place. This means that different cultures learn and adapt materials and practices from each other and the diffusion of ideas take place. This process is best explained by the Roger's (1997) diffusion of innovation theory. Diffusion, according to Rogers (1997),is the trickle-down process by which an innovation (communication idea or message) is communicated through certain channels.If a significant number of cultural differences are absorbed and a number of similarities are found, then cultural synergy takes place.

To reduce this risk of facing cultural apprehension it is, therefore, important to study and understand the cultural values both above and below 'waterline'.For example, Brown and Peacock (2007) found that academic orientation before commencement of the programme can help to prepare students for academic and cultural differences. Students participating in student exchanges should ideally receive a predeparture orientation in the home universities, with the assistance of the host university's international office. This should not only cover basic cultural knowledge and the language of the host country, but should also address expectations for classroom interactions. Leong and Ward (2000) maintain that although culture-specific knowledge is important, cultural general knowledge and understanding of some communications concepts, theories and research (e.g., communication-accommodation theory, theories of cross-cultural adjustment, anxiety uncertainty management theory and models of intercultural communication competence) can further facilitate ethical and culturally appropriate teaching and learning. Based on the above, it is evident that intercultural communication study could be used as an effective tool to ease cultural barriers and plays a critical role in the international student exchange 
programme. This article, therefore, sets out to examine the cultural communication challenges faced by international exchange students studying at a university in South Africa.

\section{Methodology}

This study was conducted at a selected university in South Africa with a formal exchange student programme. International students were used as a sample. A quantitative descriptive methodology was employed for this study.

Sample: The sample consisted of all international students from first-world countries (USA and UK) registered at the selected university in 2011.

Instrument and procedure: Themes emanating from the literature review were used to develop the research instrument. Data was collected through a census study via a questionnaire administered to ninety nine students $-100 \%$ of the international students registered at the university. Respondent profiles included both male and female second-year international students.

Data Analysis: There search results from the questionnaire were captured using the Microsoft Excel to produce quantifiable numerical data.

\section{Results and discussion}

The findings are reported and contextualised against the themes identified from the literature review.

Cultural Challenges: The results (Figure 2) show that only 13\% of the students had previously experienced living in a multicultural country. The remaining (87\%) respondents had no real-life experiences of the challenges that they were to face in a multicultural diverse environment.

\section{Figure 2: Students that had experience of living in a multicultural country}

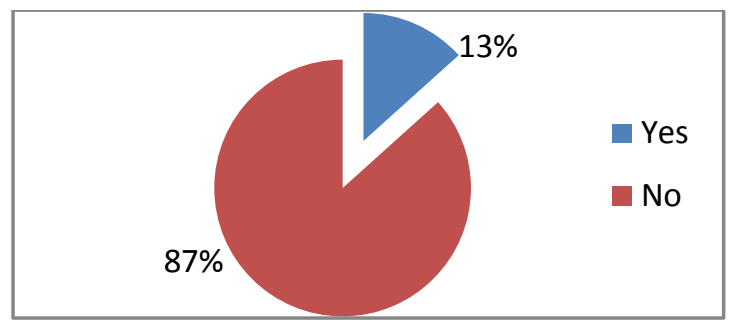

In addition, all $(100 \%)$ of the respondents contirmed that they did not receive any information from the host university regarding the challenges that they might face studying in a developing multicultural country. They indicated that we were stressed when we arrived in South Africa as it was difficult to communicate with the locals due to language and differences and the different procedures and rules from our university. These results infer that first-time visiting students may have been subjected to culture shock when confronted with South Africa's ethnically diverse culture which could have led to increased stress levels and anxiety, as explained by Brown (2008). These findings are also an indication of a lack of intercultural communication skills on how students could adapt in to foreign practices. This data is consistent with Brown's (2008) study and confirms that students are challenged not only by the demands of higher education, but they are also placed under pressure by the confrontation of an alien culture. Prior communication and information about a host country's multicultural make-up could have better prepared students for the experience. Information regarding South Africa's diverse languages and practices could become the subject matter of a culture and intercultural communication module at the home university so that students could be formally prepared not only for the foreign experience, but also how to communicate within multicultural context. Clarity of intercultural communication messages: Respondents were asked to rate the cultural clarity and usefulness of messages communicated by the host university in the form of the website, brochures, DVD and the orientation programme.

Website Messages: The findings (Figure 3) reveal that an above average number $(69 \%)$ of the respondents found the information on the website was clear and helpful. The respondents agreed that they were able to understand the message easily on the website. However they also mentioned that it 
only provided us with some information about the multi-cultural make-up of South Africa. They also indicated that this information helped us to understand only some of the language, religion, communication and cultural differences that we could have faced during our stay in South Africa. This finding confirms Rogers' (1997) argument that the trickle-down process (diffusion) or message communication could lead to cultural synergy if a certain number of similarities are present. A smaller number $(14 \%)$ of the respondents experienced difficulty in understanding the content of the message. The remaining (17\%) respondents were unsure whether the messages were clear and helpful. This may be an indication that these students were unable to fully interpret and understand the messages on the university's website or did not take the time to log onto the host university's website. Religion and cultural differences could be added as subject matter on the study module to formally prepare students to understand cultural differences and the issues relating to culture and religion. To be able to communicate and to be understood in a multicultural will ease students stress levels.

\section{Figure 3: Website messages were clear and helpful}

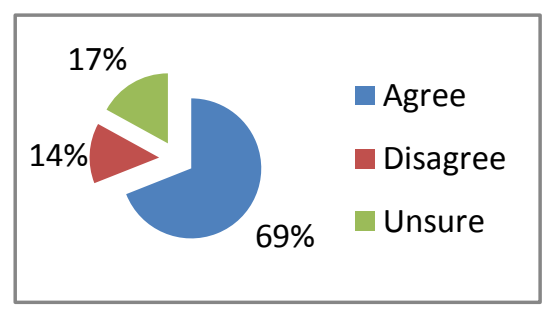

Brochure Messages: The findings (Figure 4) revealed that most (77\%) of the respondents found that the brochure did not adequately answer their questions and did not contain any valuable cultural information. A small (20\%) number of respondents did, however, feel that the brochure was adequate for their needs, whilst a smaller (3\%) number of the respondents were unsure of the clarity of the brochure. Respondents mentioned that the brochure was inadequate because it is written in local dialect. The local names and explanations were difficult to interpret. It is clear from the findings that some of the respondents had difficulty in relating to the local content in the brochure. These findings support Gundykunst's (1998) assertion that local language and culture are sources of strain for foreign students. This may have caused the student to perceive his/her own internal prejudices, which could distort the interpretation of the intended message. Clearly, perceptions and prejudices as mentioned by Funakawa's (1997) play an important role during communication with foreign students. The study of cultural perceptions and prejudices and its effects on communication can be addressed as subject matter on the study module to better prepare students for their foreign experience.

DVD Messages: The findings (Figure 4) show that only a small number (10\%) of the respondents agreed that the DVD provided a general overview of the student exchange programme. The remaining (90\%) respondents felt that the DVD did not speak specifically about the student exchange programme, but rather about the university. Respondents felt that the DVD was an ideal medium to include information about local culture and to present an overview of the residences and campus life for international students. They also felt that information relating to housing on campus should have been showcased on the DVD as the housing was not what we expected. It was full of local students and I did not relate very well to them. Respondents also mentioned that if we knew about South Africa's campus life and the multicultural makeup of students we would have been less stressed when we arrived at campus. These findings also support Gundykunst's (1998) findings that accommodation is one of the key sources of strain for foreign students. From these findings it is evident that the international exchange students' view of housing on campus was negative. This invariably contributed to the negative experience of the local culture in South Africa. Clearly, intercultural communication issues around student housing and campus life are important issues for international students. Cultural factors relating to the diverse cultures and issues around acceptable local behavior can be integrated as subject matter on the cultural study module. This information can also be communicated to students via the DVD during their study programme at their home country before they arrive in South Africa.

Orientation programme messages: The findings revealed that a small number (7\%) of the respondents strongly agreed that the quality of the orientation programme was good. The others (93\%) believed that that the quality of the orientation programme was poor. Respondents felt that orientation programme was not long enough and that there could have been an increase in the frequency of orientation 
programmes. In addition information relating to culture, safety, security and other issues was not discussed at these sessions. These responses support Peacock and Brown's (2007) suggestion that academic orientation before the commencement of the programme can help prepare students for academic and cultural differences. Findings also suggest that an extension in the duration of the orientation programme might be positive to facilitate the needs of foreign students. Moreover, students are not receiving adequate communication regarding cultural issues during the orientation programme.

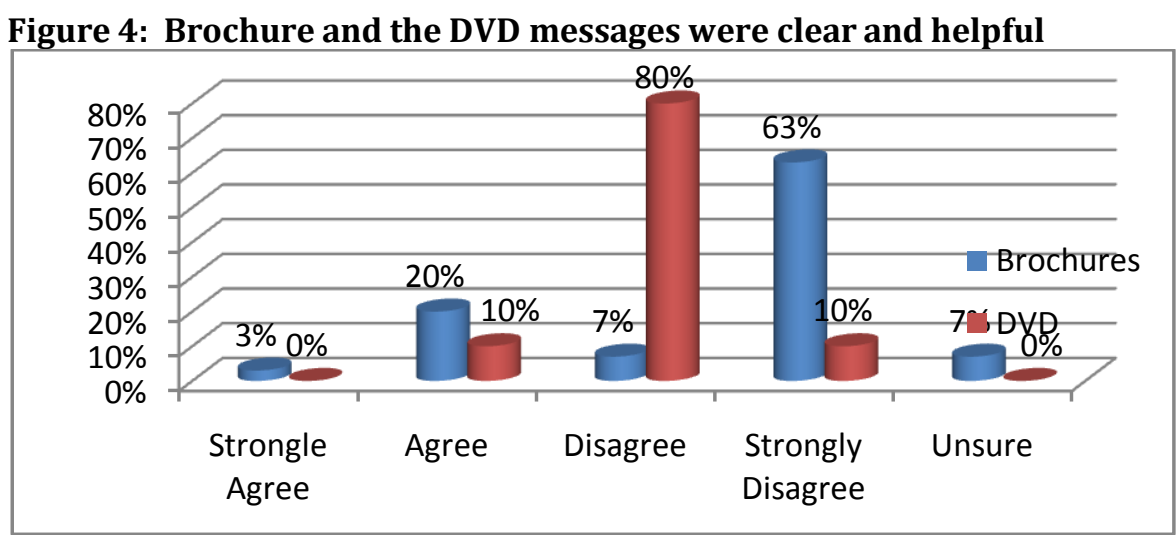

In addition, respondents mentioned that they were not happy about the information they received regarding student housing during orientation. Findings show that most students were not aware of the housing facilities and that the only information received on student housing was the rental prices. No other information was provided. Other respondents reflected that they were not informed about state of housing and did not know what to expect. I only found out when I got here that there were various cultural aspects that I did not understand and could not tolerate. These included people talking very loudly and allowing other friends to live with them. Someone should have told us about this. It is evident from the findings that there is inadequate information available to students regarding acceptable practices at university residences. This lack of communication could be a contributing factor to some of the challenges and the cultural shock faced by students living in South Africa for the first time. Evidence of cultural shock is indicated by words such as cultural aspects that I did not understand and could not tolerate. Speaking loudly in the African culture is a norm and is culturally acceptable. The lack of this knowledge resulted in personal struggle by international students as identified by Chaney and Martin (2007).

Respondents also revealed that security did not make me feel secure. I was not provided with adequate information on local laws and practices. I felt uncomfortable with the security guards as they had difficulties understanding in me. I felt that they were slightly intimidating and threatening as they were constantly calling us aside and asking questions. I could not understand what they said because of their tone of voice and language. Because of this I did not feel safe in their presence. Respondents felt intimidated, insecure and threatened as a result of the security guards 'language and voice tone. This is a clear indication of stereotyping - where the guards were labeled as precarious, due to differences in language and voice tone. These factors can be viewed as intercultural communication barriers and can, therefore, contribute to some stress experienced by the international students (Toyokawa and Toyokawa 2002).

Respondents also felt that there were not enough social and intercultural programmes for international students. They mentioned that we were not invited to any social events that were culturally valuable. One respondent mentioned that he refused to participate in any activities as I perceived the locals as being very unfriendly. I was very unhappy and could not get on with the locals. I was homesick and just wanted to return to my country. Findings are consistent with Chaney and Martin's (2007) observation that if foreign visitors do not fit into the new culture, they would perceive the experience as negative. In addition, because they did not socialize with the locals, the international experience did not enable them to learn about the local South African cultures (Van Hoof and Verbeeten, 2005).Orientation should occur before the commencement of the exchange programme as suggested by Brown and Peacock (2007). Issues that are on the orientation programme relating to housing, stereotyping, security, cultural norms, cultural values, and cultural rules could be included as subject matter of the cultural module. Central to 
this should be how these factors affect communication and how to overcome intercultural communication barriers.

\section{Conclusion}

The increase in globalization and internationalization has impacted on higher education institutions all over the world. As such, this study has end devoured to show that culture is a major challenge faced by international exchange students studying in South Africa. These challenges may threaten the growth of future exchange programmes. A possible solution to overcoming these cultural gaps is through cultural and intercultural communication study. Universities could, therefore, include intercultural communication studies as a compulsory module for all international students wanting to study in South Africa. These modules should not only address surface values such as the environment; ethnic; dress; non-verbal; religion; language and behaviour, but should also take cognisance of Funakawa's (1997) below the 'water line cultural values which such as norms; rules; networks; sub-culture groups; values; business philosophy; stereotypes and perceptions. The understanding of these values will build successful business relationships and bring about cultural synergy (Funakawa, 1997). These modules should be designed in conjunction with the South African host university and should be completed before the exchange students arrive in South Africa. This could help to acculturate international students with South Africa's culture and local practices and may assist them to adapt and adjust to the multicultural South African society. This paper therefore suggests that to add credence to the international students' experiences and the exchange programme, all first-time international students take a core study module based on culture and intercultural communication before they arrive in South Africa.

\section{References}

Altbach, P. G. \& Teichler, U. (2001).Internationalization and exchanges in a globalized university. Journal of Studies in International Education, 5(1), 5-25.

Ballard, B. \& Clanchy, J. (1997).Teaching international students: A brief guide for lecturers and supervisors. Melbourne, Australia: IDP Education.

Bond, S. \& Lemasson, J. (1999). A new world of knowledge: Canadian universities and globalization. Ottawa: International Development Research Centre.

Brown, L. (2008). The incidence of study-related stress in international students in the initial stage of the international sojourn. Journal of Studies in International Education, 12(1), 5-28.

Brown, L. (2009). A failure of communication on the cross-cultural campus. Journal of Studies in International Education, 13(4), 439-454.

Brown, L. \& Peacock, N. (2007). Crisis of cross cultural communication on our campuses. Paper presented at the 2nd International Conference in Education for Sustainable Development: Graduates as Global Citizens, 10-11 Sept. 2007, Bounemouth, UK.

Chaney, L. H. \& Martin, J. S. (2007). Intercultural business communication. Upper Saddle River, N.J: Pearson Prentice Hall.

Funakawa, A. (1997). Transcultural Management. San Francisco, CA: Jossey-Bass.

Gundykunst, W. (1998). Binding Differences: Effective Intergroup Communication. London: Sage.

Jandt, A. (2000). Intercultural Business Communication. 4thed. New Jersey: Pearson Education.

Kishun, R. (2007). The internationalization of higher education in South Africa: Progress and challenges. Journal of Studies in International Education, 11(3-4), 455-469.

Leong, C. H. \& Ward, C. (2000). Identity conflict in sojourners. International Journal of Intercultural Relations, 24(6), 763-776.

Lin, Y. \& Rancer, A. S. (2003). Ethnocentrism, intercultural communication apprehension, intercultural willingness-to-communicate, and intentions to participate in an intercultural dialogue program: Testing a proposed model. Communication Research Reports, 20(1), 62-72.

Persaud, R. (1993). The loneliness of the long-distance student. Journal of International Education, 4(1), 45-51.

Rogers, M. E. (1997). Diffusion of innovation theory. (Online) Available at: http://mlm.gov/pnr/eval/rogers.html (Accessed 10 December 2012).

Samovar, L. A., Porter, R. E. \& McDaniel, E. R. (2011). Intercultural communication: A reader. Boston: Wadsworth Publishing Company. 
Taylor, J. (2004). Toward a strategy for internationalization: Lessons and practice from four universities. Journal of Studies in International Education, 8(2), 149-171.

Toyokawa, T. \&Toyokawa, N. (2002). Extracurricular activities and the adjustment of Asian international students: A study of Japanese students. International Journal of Intercultural Relations, 26(4), 363-379.

Van Hoof, H. B. \& Verbeeten, M. J. (2005). Wine is for drinking, water is for washing: Student opinions about international exchange programs. Journal of Studies in International Education, 9(1), 42-61. 